\title{
ESTIMATION MODEL AND SELECTION METHOD \\ OF PANEL DATA REGRESSION : AN OVERVIEW OF COMMON \\ EFFECT, FIXED EFFECT, AND RANDOM EFFECT MODEL
}

\author{
Author \\ Rizka Zulfikar, STp, MM \\ Fakultas Ekonomi \\ Universitas Islam Kalimantan MAB Banjarmasin
}

Regression analysis of panel data is a data structure which is panel data. Generally, parameter estimation in the regression analysis with cross section data is done by estimating the least squares method called Ordinary Least Square (OLS). Regression Method Data Panel will give the result of estimation which is Best Linear Unbiased Estimation (BLUE).

Data Panel Regression is a combination of cross section data and time series, where the same unit cross section is measured at different times. So in other words, panel data is data from some of the same individuals observed in a certain period of time. If we have $\mathrm{T}$ time periods $(\mathrm{t}$ $=1,2, \ldots, \mathrm{T})$ and $\mathrm{N}$ the number of individuals $(\mathrm{i}=1,2, \ldots, \mathrm{N})$, then with panel data we will have total observation units of $\mathrm{N} \times \mathrm{T}$.

If sum unit time is the same for each individual, then the data is called balanced panel. If instead, the number of time units is different for each individual, then it is called the unbalanced panel.

While other data types, namely:time-series data and cross-section. In time series, one or more variables will be observed on one observation unit within a certain time frame. While data cross-section is the observation of several units of observation in a single point of time.

\section{Regression Stages of Panel Data}

Unlike the usual regression, panel data regression must go through the precise estimation modeling step. The following table diagram of the panel data regression is as follows :

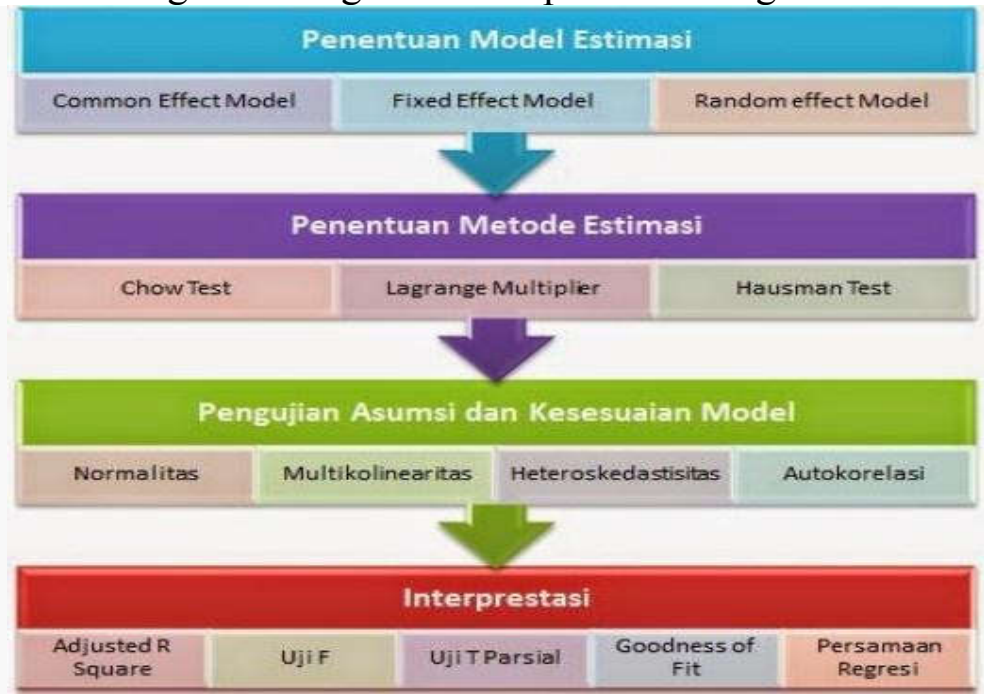


Stage Of Panel Data 


\section{ESTIMATION MODEL OF PANEL DATA REGRESSION}

In the method of estimating the regression model using panel data can be done through three approaches, among others:

(1) Common Effect Model or Pooled Least Square (PLS)

A panel data model approach is most simply because it combines only time series and cross section data. In this model is not considered time and individual dimensions, so it is assumed that the behavior of corporate data is the same in various periods. This method can use the Ordinary Least Square (OLS) approach or the least squares technique to estimate the panel data model.

The form of panel data regression equation is similar to ordinary least square, ie:

$$
y_{i t}=\alpha+\boldsymbol{\beta}^{\prime} \boldsymbol{X}_{i t}+\varepsilon_{i t}
$$

Common Effect Equation

Description:

For $\mathrm{i}=1,2, \ldots ., \mathrm{N}$ and $\mathrm{t}=1,2, \ldots ., \mathrm{T}$.

Where $\mathrm{N}=$ Number of individuals or cross section and $\mathrm{T}$ is the number of time periods. From this model NxT can be generated equation, that is equal to $\mathrm{T}$ equation of cross section and as much $\mathrm{N}$ equation coherent time or time series.

The common effects effect example is as follows:

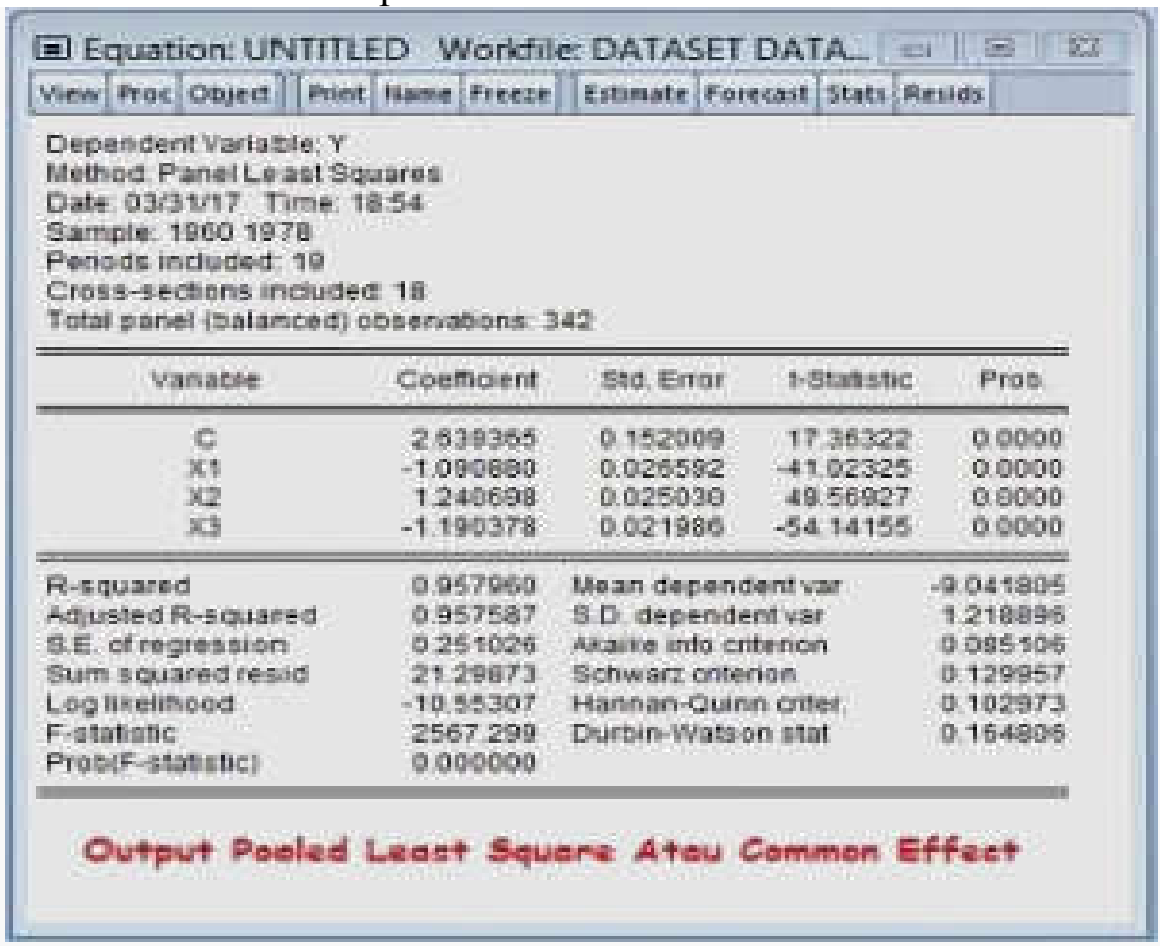

Common Effect Output of Data Panel Regression with Eviews 
Based on the above output, the Summary of Regression Result Panel Data Common Effects Model is:

1. Periods Include: Is the number of period or sequence of time involved in the analysis. Where in this panel data regression example, the period used is 1968 to 1978. So the number of years used in the analysis is as much as 19 years.

2. Cross section Include: The number of cross sections or panels involved in the analysis. Where in this panel data regression example, the panel used is a country whose number is as many as 18 countries.

3. Total Panel (Balanced) observations: is the number of observations involved in the analysis. The term balanced means balance, ie the amount of time (year) used each panel (state) is the same or constant. So the calculation is $19 \times 18=342$ observations.

4. Variable Column: is a list of variables that are analyzed. Where in this panel data regression example use $\mathrm{Y}$ as response variable. While predictor variables are $\mathrm{X} 1, \mathrm{X} 2$ and $\mathrm{X} 3$. And $\mathrm{C}$ as the residual or error of the panel data regression equation.

\section{Hypothesis Regression Panel Data Model Common Effects}

1. R Square: is the magnitude of the influence or ability of predictor variables simultaneously in describing the response variable. If the value is more than 0.5 then the ability of the predictor variable is strong in explaining the response variable. While vice versa if the value is less than 0.5 then the ability of the predictor variable is not strong in explaining the response variable. In this panel data regression example, the $\mathrm{R}$ Square value is 0.9579 , which means that the predictor variable is very strong in explaining the response variable.

2. Adjusted R Square: is the magnitude of the influence or ability of predictor variables simultaneously in explaining the response variable by observing the standard error. the explanation is the same as R Square but this value has been corrected with standard error.

3. F-Statistics: is the value of Test $F$ which is a simultaneous test of panel data regression. This $\mathrm{F}$ value indicates the significance level of influence of predictor variable to response variable. To use this $\mathrm{F}$ value must be compared with $\mathrm{F}$ Table. But to facilitate can directly see the value of Prob (F-Statistics).

4. Prob (F-Statistics): is the $\mathrm{p}$ value of the $\mathrm{F}$ test which is the significance level of the $\mathrm{F}$ value, that is to assess the simultaneous influence of the predictor variable to the response variable whether statistically significant or not. If the value of $p$ value is less than the critical limit eg 0.05 then accepting $\mathrm{H} 1$ or which means simultaneous influence of predictor variable to the response variable proved statistically significant. Vice versa if the value of $p$ value is more than the critical limit then accept H0 or which means the simultaneous influence of predictor variables to the response variable is not proven statistically significant.

\section{(2) Fixed Effect Model (FE)}

This model assumes that differences between individuals can be accommodated from different intercept. To estimate Fixed Effects model panel data using a dummy variable technique to capture the differences between intercept companies, different intercept can occur due to differences in work, managerial, and incentive cultures. Nevertheless the intercept same between companies. This estimation model is often also called the technique of Least Squares Dummy Variable (LSDV).

The Fixed effect model differs from the common effect, but still uses the ordinary least square principle. The assumption of modeling that produces a constant intercept for each 
cross section and time is considered less realistic, so more models are needed to capture the difference.

Fixed effects assume that differences between individuals (cross section) can be accommodated from different intercept. In order to estimate the Fixed Effects Model with different intercept between individuals, the dummy variable technique is used. Such estimation models are often referred to as the Least Squares Dummy Variable technique or abbreviated LSDV.

The regression equation of fixed effects model panel data is as follows:

$$
y_{i t}=\alpha_{i}+\boldsymbol{\beta}^{\prime} \boldsymbol{X}_{i t}+\varepsilon_{i t}
$$

Fixed Effect Equation

Description:

for $\mathrm{i}=1,2, \ldots ., \mathrm{N}$ and $\mathrm{t}=1,2, \ldots ., \mathrm{T}$.

Where $\mathrm{N}=$ number of individuals or cross section and $\mathrm{T}=$ the number of time periods.

The output of fixed effect for example is as follows

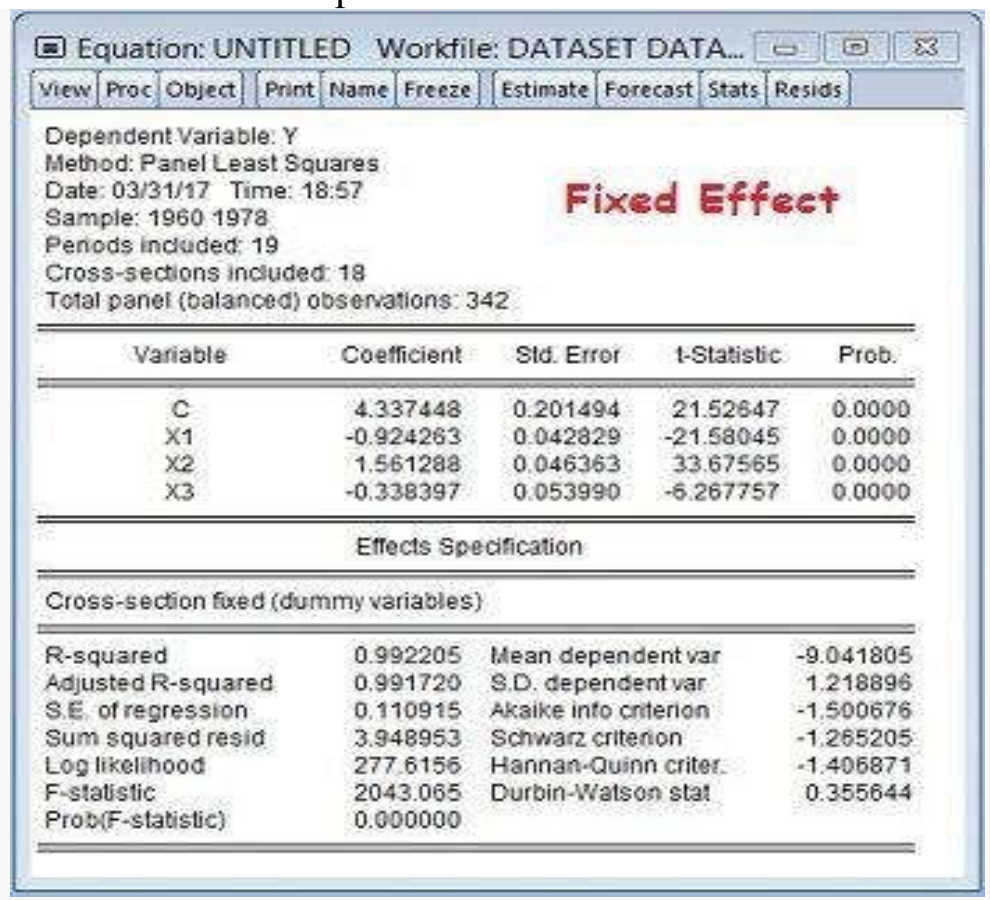

Output Fixed Effect Data Panel Regression with Eviews

How to Read Regression Result Panel Data Model Fixed Effect same with how to read Regression Result Panel Data Model Common Effect. What distinguishes is the value only and the form of panel data regression equations based on beta coefficients.

\section{Random Effect Model (RE)}

This model will estimate panel data where interference variables may be interconnected between time and between individuals. In the Random Effect model, the difference between intercepts is accommodated by the error terms of each company. The advantage of using the 
Random Effect model is to eliminate heteroscedasticity. This model is also called the Error Component Model (ECM) or Generalized Least Square (GLS) technique.

In principle, the random effect model is different from the common effect and fixed effect, especially this model does not use the principle of ordinary least square, but using the principle of maximum likelihood or general least square.

Output random effect example is as follows:

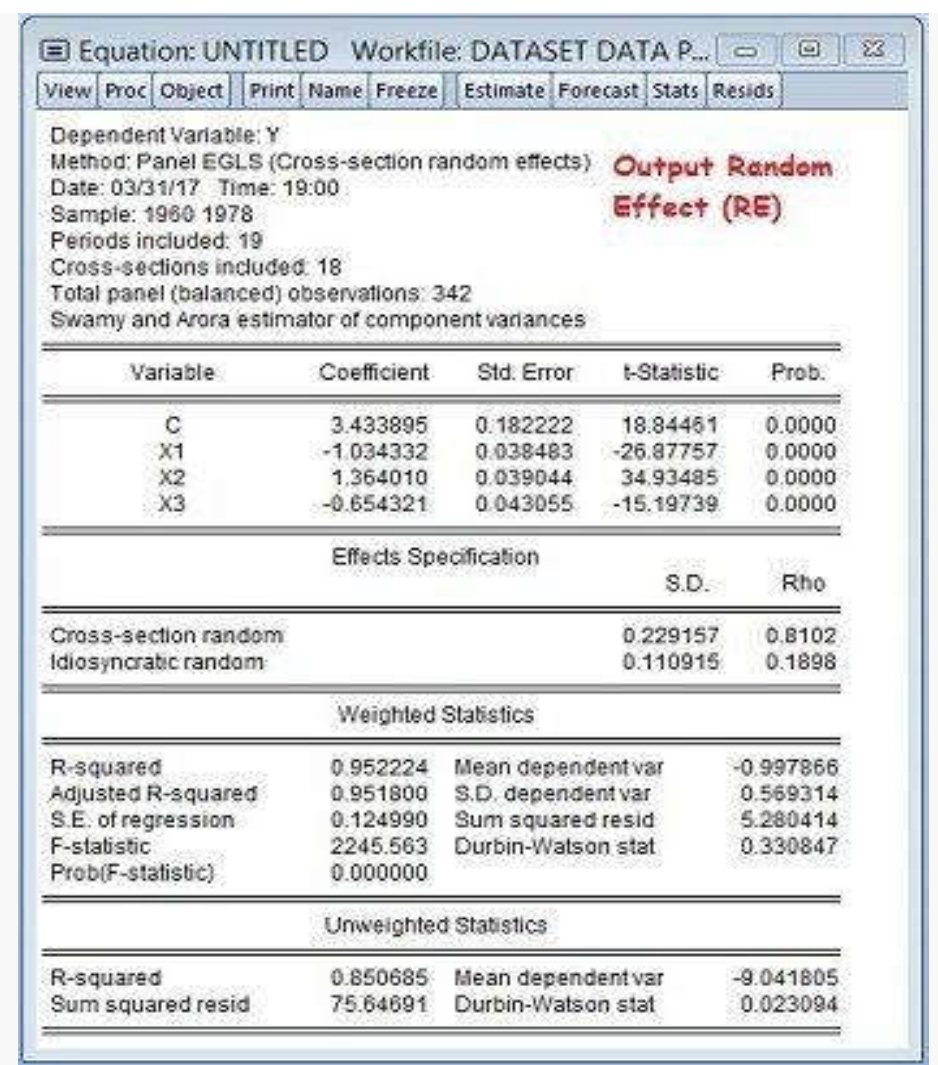

Random Effect Output Regression Data Panel with Eviews

How to read output on random effect is not much different with common effect or fixed effect. Only in eviews we will see two outputs that are weighted and unweighted. If we use Fixed Effects through LSDV techniques, it will show the uncertainty of the model used. This random effect model is useful to solve the problem by using residual variable.

In the random effect model, residuals may be interconnected between time and between individuals or cross sections. Therefore, this model assumes that there is a difference of intercept for each individual and the intercept is a random variable. So in the random effect model there are two residual components. The first is the residual as a whole where the residual is a combination of cross section and time series. The second residual is an individual residual which is a random characteristic of the $i$-th unit observation and remains at all times.

The regression equation of panel data of random effects model is as follows:

$$
y_{i t}=\alpha+\boldsymbol{\beta}^{\prime} \boldsymbol{X}_{i t}+u_{i}+\varepsilon_{i t}
$$

Random Effect Equation 
Description:

for $\mathrm{i}=1,2, \ldots ., \mathrm{N}$ and $\mathrm{t}=1,2, \ldots ., \mathrm{T}$.

Where:

$\mathrm{N}=$ number of individuals or cross section

$\mathrm{T}=$ the number of time periods.

Eit $=$ is the residual as a whole where the residual is a combination of cross section and time series.

$\mathrm{Ui}=$ is the individual residual which is the random characteristic ofunit observation the $\mathrm{i}$-thand remains at all times.

\section{Selection Method of Regression Data Panel}

To select the most appropriate model, there are several tests that can be done, such as :

(1) Chow Test

Chow test is a test to determine the model of whether Common Effect (CE) or Fixed Effect (FE) is most appropriately used in estimating panel data .

If Results:

H0: Select CE $(p>0.05)$

H1: Select FE $(p<0.05)$

(2) Hausman Test

Hausman test test is a statistical test to select whether the most appropriate Fixed Effect or Random Effect model is used.

If Result:

H0: Select RE $(\mathrm{p}>0.05)$

H1: Select FE $(\mathrm{p}<0.05)$

(3) Test Lagrange Multiplier Lagrange multiplier

test (LM) is a test to determine whether Random Effect model is better than Common Effect (PLS) method used.

If Result:

H0: Select CE $(\mathrm{p}>0.05)$

H1: Select RE $(\mathrm{p}<0.05)$

From the three tests to determine the Estimation Method above, illustrated in the graph below: 


\section{PLS}
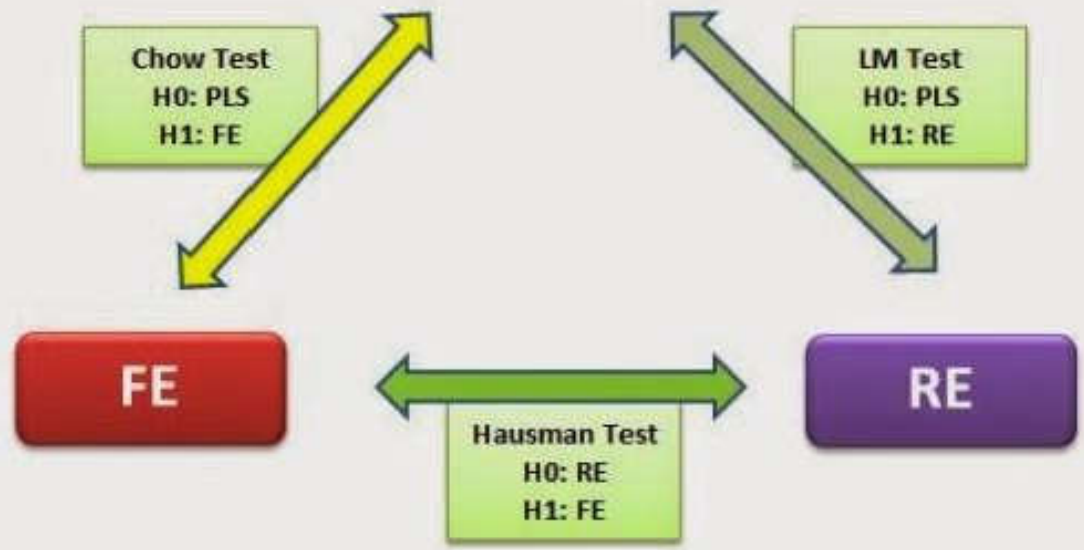

Choice of Regression Estimation of Panel Data

\section{Chow Test}

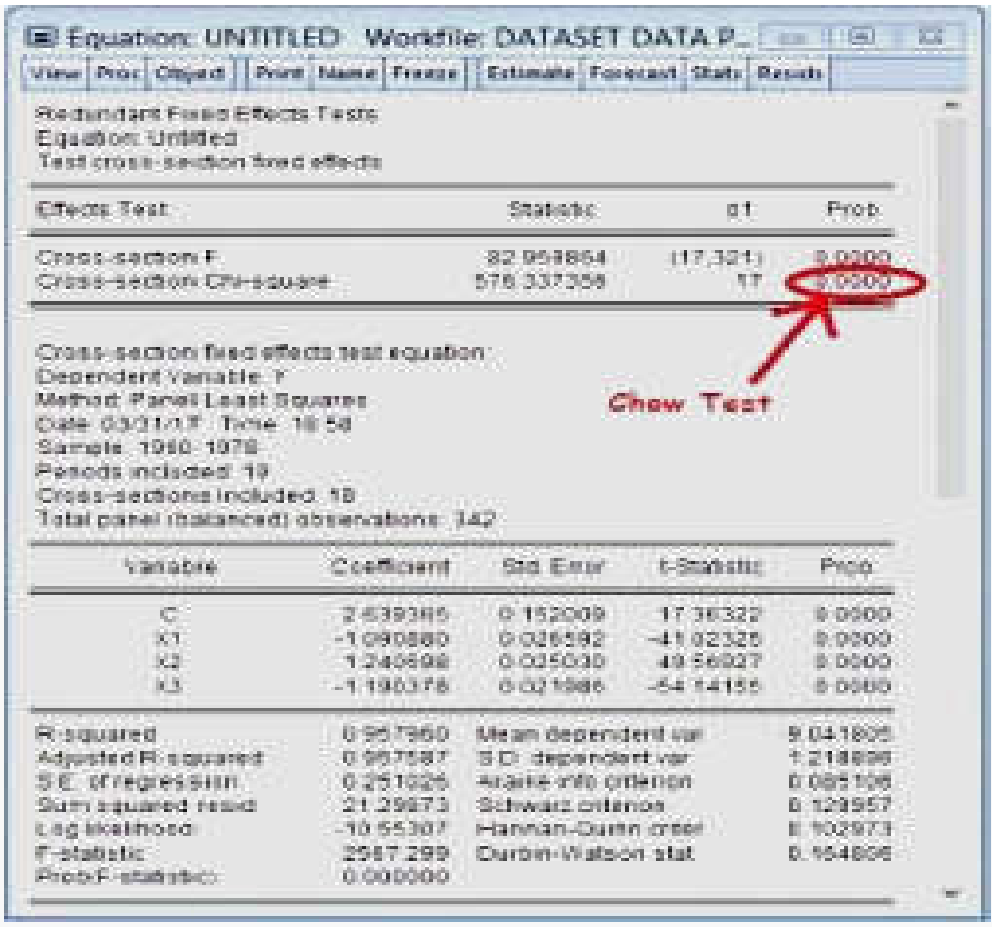

Output Chow Test Data Regression Panel with Eviews

Consider the output above, which is on the line "Cross-section Chi-square" column Prob. (In the red circle picture above). Where in this tutorial the value is 0.0000 . How to interpret Chow Test based on that value. That is if the value of Prob. Cross-section Chi-square $<0.05$ then we will choose fixed effect from the common effect. And vice versa if the value $>0.05$ then we will choose the common effect. 
Based on the image above, then in this tutorial prob value of $0.000<0.05$ then chow test choose fixed effect.

\section{Stages After Chow Test}

If the chow test chooses a fixed effect, then the next step is to do a random effect then do a hausman test to select fixed effectorrandom effects. But if chow test turns out to choosecommon effect, then the next step that must be done israndom effectthentesttest Lagrangian multiplier testto determine whether to choose common effect or random effect.

\section{Hausman Test Test}

\section{Objectives Hausman Test with Eviews}

Hausman test or often referred to as Hausman Test is a test used to determine the best method between fixed effect or random effect. If we have entered the post-chow test stage and the result is to choose fixed effect, then it should be continued with hausman test. The requirement is to perform steps in a sequence, which is doing a fixed effect analysis first and then proceed with a random effect.

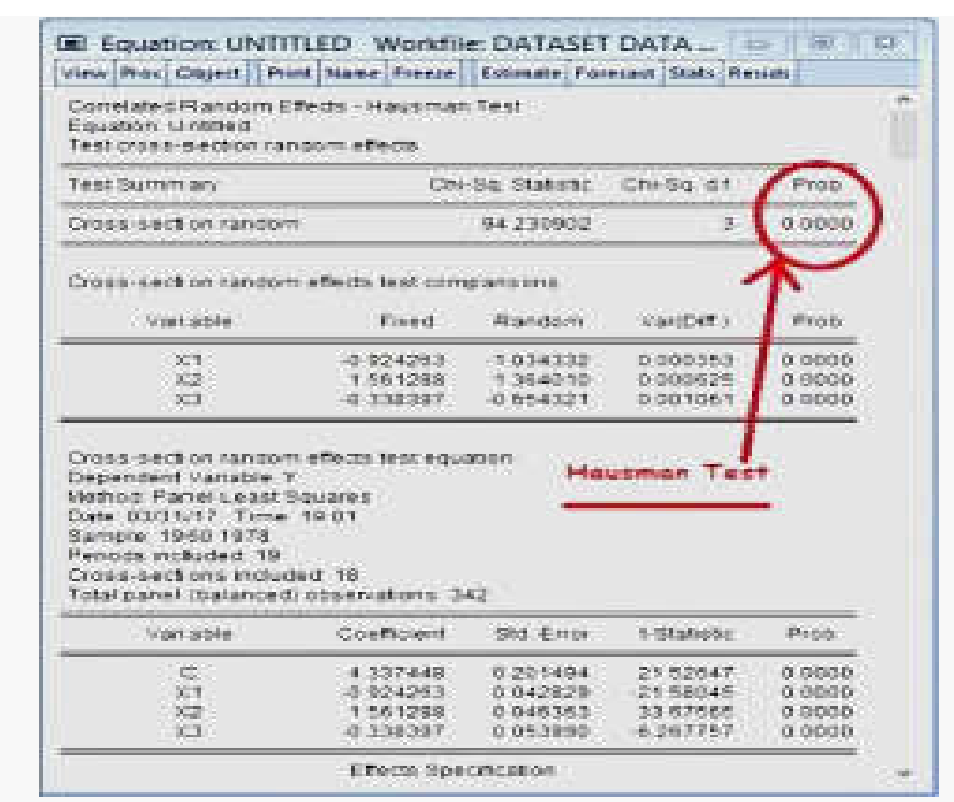

Output Hausman Test Data Panel Regression with Eviews

Which must be considered from the Hausman Test output with Eviews above, that is on the value that is in the red circle. The value is the $\mathrm{p}$ value of the test hausman test, which in this tutorial is worth 0.0000 . Value P Value 0.000 less than 0.05 then receive $\mathrm{H} 1$ which means the best method that must be used is fixed effect from the random effect.

\section{The Conclusion Of Hausman test}

The conclusion that we must make when finished doing hausman test with eviews is :

1. If Hausman Test accept $\mathrm{H} 0$ or $\mathrm{p}$ value $>0,05$ then method we choose is random effect. Then we proceed with Lagrangian Multiplier test to determine whether we still choose Random effect or Common effect.

2. If Hausman Test receives $\mathrm{H} 1$ or $\mathrm{p}$ value $<0,05$ then method we choose is fixed effect. 


\section{Lagrange Multiplier Test with Eviews}

\section{Understanding Lagrange Multiplier Test}

Lagrange Multiplier Test Test or commonly referred to as Lagrangian Multiplier Test is an analysis performed with the aim to determine the best method in panel data regression, whether to use common effect or random effect. The Lagrange Multiplier test has a function to determine the best estimate, whether using a random effect or not.

\section{The purpose of Lagrange Multiplier Test}

Lagrange Multiplier Test Test with this eviews should be done if we are in two conditions when doing data panel regression, namely:

1. The Chow Test shows that the best method is the Common Effect of the fixed effect. So the next step to determine whether the Common Effect is better than the Random Effect, then the Lagrange Multiplier Test is required.

2. The Hausman Test test shows that the best method is the Random effect of the Fixed Effect. So the next step to determine whether the Random Effect is better than the Common Effect, then the Lagrange Multiplier Test is required.

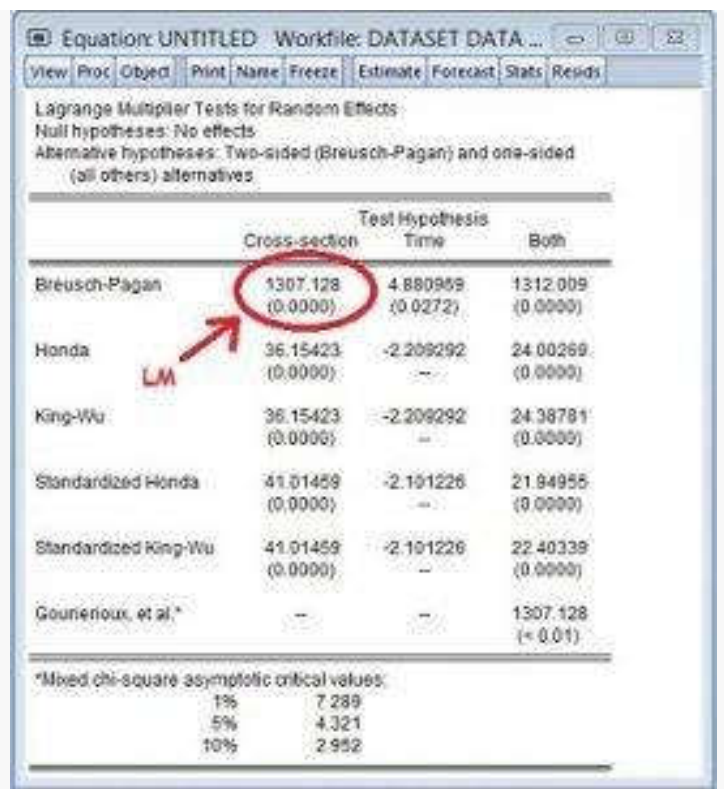

Output Lagrange Multiplier Test Data Panel Regression with Eviews The

value of $\mathrm{P}$ Value is shown by the number below which is 0.000 where the value is less than 0.05. So the Lagrange Multiplier Test indicates that receiving H1 means the best estimation method is Random Effect. If the value of $\mathrm{p}$ value is greater than 0.05 then receive H0 which means the best estimation method is Common Effect. 